\title{
Prospective associations with physiological, psychosocial and educational outcomes of meeting Australian 24-Hour Movement Guidelines for the Early Years
}

Trina Hinkley ${ }^{1}$, Anna Timperio ${ }^{1}$, Amanda Watson², Rachel L. Duckham ${ }^{1,3}$, Anthony D. Okely ${ }^{4,5}$, Dylan Cliff ${ }^{4,5}$, Alison Carver ${ }^{1,6}$ and Kylie D. Hesketh ${ }^{1 *}$ (D)

\begin{abstract}
Background: Several countries have released movement guidelines for children under 5 that incorporate guidelines for sleep, physical activity and sedentary behavior. This study examines prospective associations of preschool children's compliance with the 24-Hour Australian movement guidelines (sleep, physical activity, screen time) and physiological, psychosocial and educational outcomes during primary school.

Methods: Data were from the Healthy Active Preschool and Primary Years Study (Melbourne, Australia; $n=471 ; 3-5$ years; 2008/9). Follow-ups occurred at 3 (2011/12; 6-8 years), 6 (2014/15; 9-11 years) and 7 (2016; 10-12 years) years post baseline. Multiple regression models assessed associations between compliance with guidelines at baseline and later outcomes.

Results: Children were 4.6 years at baseline (53\% boys; $62 \%$ high socio-economic families). Most children met physical activity (89\%) and sleep (93\%) guidelines; $23 \%$ met screen-time guidelines; and 20\% met all guidelines at baseline. Meeting all of the three guidelines was associated with lower BMI z-scores at 9-11 years of age $(b=-0.26$, $95 \% \mathrm{Cl}-0.47,-0.05)$. Meeting physical activity guidelines was associated with higher total body bone mineral density $(b=0.64,95 \% \mathrm{Cl} 0.15,1.13)$, and total body bone mineral content $(b=183.19,95 \% \mathrm{Cl} 69.92,296.46)$ at $10-12$ years of age. Meeting sleep guidelines was associated with better reading $(b=37.60,95 \% \mathrm{Cl} 6.74,68.46)$, spelling $(b=34.95,95 \% \mathrm{Cl} 6.65,63.25)$, numeracy $(b=39.09,95 \% \mathrm{Cl} 11.75,66.44)$, language $(b=44.31,95 \% \mathrm{Cl} 11.77,76.85)$ and writing $(b=25.93,95 \% \mathrm{Cl} 0.30,51.57)$ at $8-9$ years of age. No associations were evident for compliance with screentime guidelines or for psychosocial outcomes.

Conclusions: Compliance with different movement behavior guidelines was associated with different outcomes. Strategies to support children in meeting all of the guidelines are warranted to maximize health and educational outcomes. Future research investigating dose-response associations, and potential mechanisms, is necessary.
\end{abstract}

Keywords: Movement behaviours, Physical activity, Sedentary behavior, Sleep, Early childhood, Psychosocial, Physiological, Educational achievement

\footnotetext{
* Correspondence: kylie.hesketh@deakin.edu.au

${ }^{1}$ Institute for Physical Activity and Nutrition (IPAN), School of Exercise and Nutrition Science, Deakin University, 1 Gheringhap Street, Geelong, VIC 3220, Australia

Full list of author information is available at the end of the article
}

(c) The Author(s). 2020 Open Access This article is distributed under the terms of the Creative Commons Attribution 4.0 International License (http://creativecommons.org/licenses/by/4.0/), which permits unrestricted use, distribution, and reproduction in any medium, provided you give appropriate credit to the original author(s) and the source, provide a link to the Creative Commons license, and indicate if changes were made. The Creative Commons Public Domain Dedication waiver (http://creativecommons.org/publicdomain/zero/1.0/) applies to the data made available in this article, unless otherwise stated. 


\section{Introduction}

Recent paradigm shifts in guideline development [1-3] have produced 24-Hour integrated movement guidelines. Such guidelines recognize the importance of physical activity (PA), sedentary behavior (SB) - including sedentary screen-time - and sleep. These guidelines should be considered individually and in combination when examining impact on children's outcomes $[4,5]$. Evidence in schoolaged populations suggests those engaged in desirable combinations of PA (e.g. high moderate- to vigorousintensity PA), SB (e.g. low screen-time) and sleep (e.g. high duration) exhibit more beneficial outcomes compared with those engaged in less desirable combinations [5-7]. However, less is known about how preschoolers' (roughly $3-5$ years of age) behaviors [8-11] are associated with future outcomes [12, 13].

Although age ranges vary, recently released Australian (3-5 year olds) and Canadian and World Health Organisation (3-4 year olds) guidelines [2, 3, 14] recommend that a healthy 24-Hour for preschoolers should comprise: $\geq 180 \mathrm{~min}$ of total PA (light-, moderate- and vigorous-intensity $\mathrm{PA}$ ), with $\geq 60 \mathrm{~min}$ in energetic play (moderate- to vigorous-intensity PA); sedentary screentime of $\leq 1 \mathrm{~h}$; and $10-13 \mathrm{~h}$ of good quality sleep. The Behavioural Epidemiology Framework suggests that an essential element of determining if a behavior should be targeted for intervention is determining associations between the behavior and health or developmental outcomes [15]. Guidelines were informed by available evidence $[2,16]$ which was synthesized in a number of systematic reviews [8-11]. Those reviews suggest that health behaviors during the preschool years are associated with multiple outcomes during later years. For instance, physical activity was favorably associated with motor development, fitness, bone and skeletal health [10]. Screen time sedentary behaviors were unfavorably associated with indicators of adiposity, motor or cognitive development, and psychosocial health [11]. Poorer sleep behaviors were associated with higher levels of adiposity, poorer emotional regulation, impaired growth, and higher risk of injuries [9]. Few studies have investigated combinations of behaviors and associations with outcomes [8]. Findings from studies identified suggest that the most ideal combinations of behaviors are favorably associated with motor development and fitness and not associated with adiposity or growth among preschool-aged children [8].

Recent studies suggest compliance with all movement guidelines is low, ranging from 4.3 to $14.9 \%$ [17-19] and longitudinal associations with health and developmental outcomes are not well established. Of the few studies in preschoolers which examine multiple behaviors concurrently (both as continuous variables and compliance with guidelines), only 3 have used a prospective design across 1 [20], 2 [21] and 4 [22] year follow-ups. However, those studies have only examined associations with adiposity [20-22] and bone health [22]. Across studies, null associations were reported between behaviors and indicators of adiposity, and small associations between physical activity and indicators of bone health were evident [22].Thus, evidence is lacking of the prospective associations of preschoolers' guideline compliance with later physiological, psychosocial and educational outcomes. A few studies have recently been published investigating preschoolers' compliance with the 24 Hour movement guidelines and various outcomes either cross-sectionally or following up to 4 year follow-ups. However, this study is the first to investigate associations of preschoolers' compliance with those guidelines and associations with physiological, psychosocial and educational outcomes up to 7 years post baseline. Using the Behavioural Epidemiology Framework as a foundation, the aims of this paper were to explore:

1. preschoolers' compliance with movement (PA, SB and sleep) guidelines;

2. prospective associations between compliance with each guideline and outcomes during primary school; and

3. prospective associations between compliance with all three guidelines and outcomes during primary school.

\section{Methods}

\section{Study setting and participants}

Data were from the Healthy Active Preschool and Primary Years (HAPPY) Study. Figure 1 presents a flow chart of participants. As previously reported [23], 65 preschools (where children attend for an educational program) and 71 long day-care centers (where children attend for child care which may also include an educational program) participated in the study. This represented $47 \%$ of 137 preschools and $46 \%$ of 156 long daycare centers invited, in randomly selected low-, mid- and high-socioeconomic areas of metropolitan Melbourne, Australia (2008/9; T1). At baseline, 1002 families (11\% of the 9494 invited families) participated, of which 766 (76\%) provided consent for re-contact. Children were eligible to participate if they were aged $3-5$ years of age and enrolled at a participating center. There were no exclusion criteria. Follow-ups were undertaken in 2011/2 when children were aged 6-8 years (T2: 567 [74\%] participated) and 2014/5 when children were aged 9-11 years (T3: 568 [76\%] participated). A sub sample of HAPPY participants $(n=208)$ with previous objective measurements of sedentary behaviour from baseline (T1) and at least one other time point (T2 or T3) were identified from the pool of 450 children remaining in the study. Those participants were stratified into tertiles at each time point based on mean sedentary behaviour 


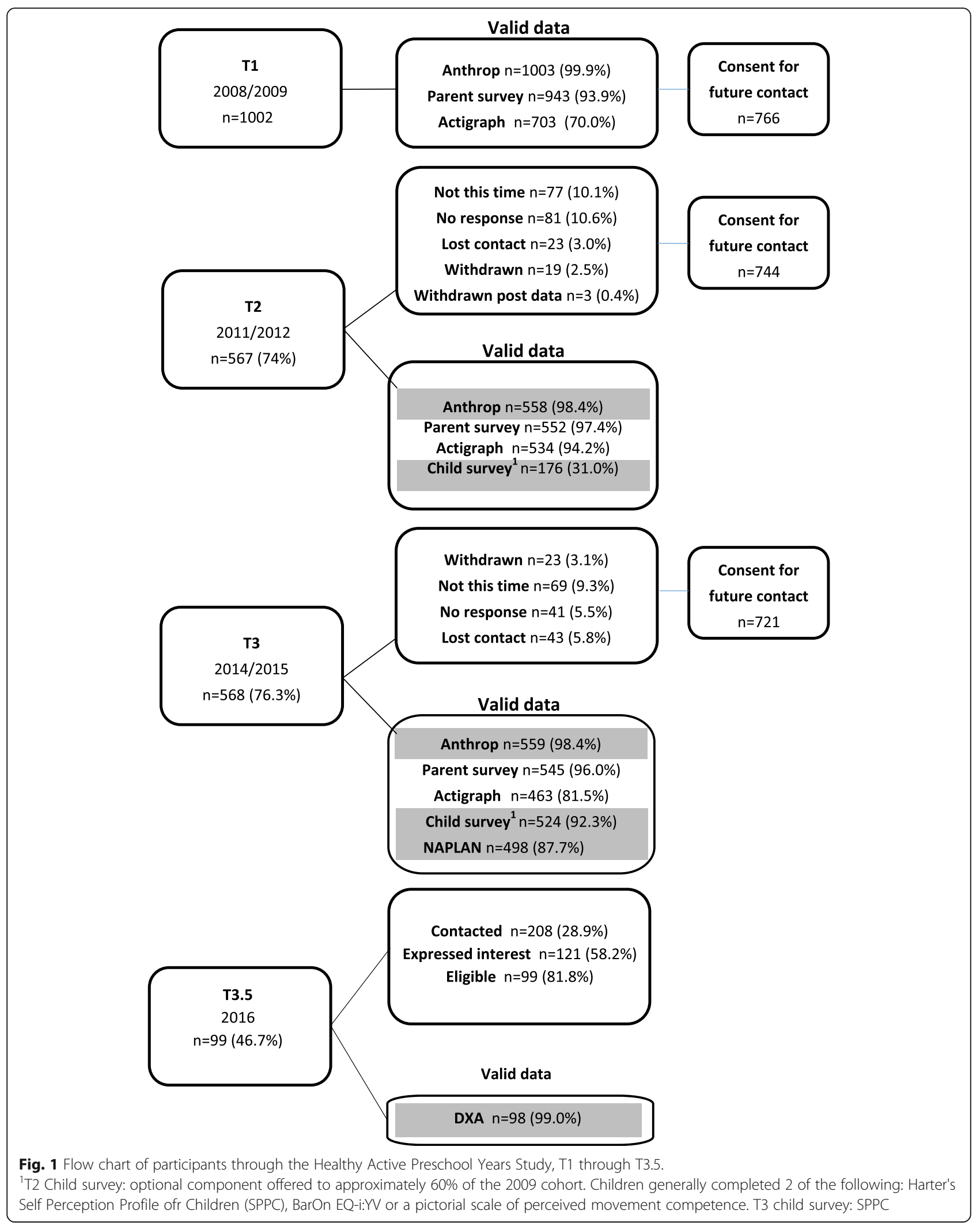


z-scores. The z-scores were internally generated within the HAPPY sample based on the sample mean and standard deviation at each timepoint. To recruit participants with contrasting sedentary behaviour levels, those consistently (at each time point they provided data) in the top and bottom tertiles for sedentary behaviour were invited to participate in the sub study. This resulted in a sub sample of 99 (girls $=45)$ (mean age $12.2+0.8$ years) providing bone outcome data for this paper in 2016 (T3.5).

The Deakin University Human Research Ethics Committee (EC291-2007) and the Victorian Department of Education and Early Childhood Development provided ethical approval for the study. Reporting of this study complies with the STROBE guidelines [24, 25].

\section{Measures \\ Exposure variables}

Physical activity (T1) Children wore ActiGraph GT1M accelerometers (on an elastic belt at the right hip during waking hours, removing for bathing, swimming) for 8 days at T1. ActiGraph accelerometers have established validity, reliability and utility [26]. Data were collected in 15-s epochs [26, 27]. The fourth complete minute of counts above zero after $4 \mathrm{am}$, with a 1-min (4-epoch) tolerance indicated daily monitoring start-times. Consecutive zero counts for $\geq 20$-min indicated non-wear time; days with $>18$-h of data were considered improbable and data removed for that day. Children with data for $\geq 6 \mathrm{~h} /$ day on $\geq 3$ week and $\geq 1$ weekend days were included in analyses [28]. A cut-point of $\geq 25$ counts per $15 \mathrm{~s}$ epoch identified time in total PA, and $\geq 420$ counts per $15 \mathrm{~s}$ epoch identified time in moderate- to vigorousintensity physical activity (MVPA) [29]. Mean time (minutes per day) engaged in total PA, and mean time in MVPA, were calculated. Children met the PA guideline if they had an average of $\geq 3 \mathrm{~h} / \mathrm{d}$ of total PA and $\geq 1 \mathrm{~h} / \mathrm{d}$ of MVPA across monitoring time [2, 3].

Screen-time (T1) Parents reported their child's week (Monday-Friday) and weekend (Saturday-Sunday) sedentary screen-time in TV/DVD/video viewing, internet/computer use and electronic games using a reliable survey [30] at T1. Average daily screen-time was computed and children met the screen-time guideline if this was $\leq 1 \mathrm{~h} / \mathrm{d}$.

Sleep (T1) Parents reported the duration of their child's usual night- and day-time sleep at T1. Total daily sleep time was calculated, previously shown to provide a reliable estimate of children's sleep [30]. Children who slept $10-13 \mathrm{~h} / \mathrm{d}$ on average met the sleep guideline.
Compliance with all guidelines (T1) Children were determined to be compliant with all guidelines if they met each of the three individual guidelines described above.

\section{Outcome variables \\ Physiological outcomes}

Adiposity (T1, T2, T3) At T1, T2 and T3, researchers measured children's height and weight using Wedderburn Seca portable rigid stadiometers, and Wedderburn Tanita portable digital scales respectively, following standardized measurement procedures [31, 32]. BMI z-scores, adjusted for age and sex [33], were calculated. Waist circumference was measured at the umbilicus at T2 and T3 using a steel, non-stretch tape measure. All measures were taken twice. If measurements differed by $>0.5 \mathrm{~cm},>0.5 \mathrm{~kg}$ or $>1.0 \mathrm{~cm}$, respectively, a third measure was taken and the average of the closest 2 used in analyses.

Bone measures, density and fractures (T3.5) Total body (less head) and lumbar spine (L2-L4) bone mineral density (BMD) and bone mineral content (BMC) were obtained using dual energy X-ray absorptiometry (Lunar IDXA, GE Healthcare Madison, WI) at T3.5 $(N=98)$. All scans used the same positioning technique and were analyzed by a single operator using Encore version 16 software. All BMD and BMC results were compared to the GE Lunar internal reference database to generate and report age specific z-scores. Parents reported their child's fracture history.

\section{Psychosocial outcomes}

Social and emotional skills (T2) The BarOn Emotional Quotient Inventory-Youth (EQi-YV; short version) assessed social and emotional skills $(n=108 ;$ T2). The instrument has acceptable validity and reliability [34]. The 30-item EQi-YV, contributing to a total score for emotional intelligence, was administered individually to children. Response options were on a 4-point Likert scale ("not true of me" to "very much true of me"). Total scores were standardised $(\mu=100, \mathrm{SD}=15)$. Higher scores represent more favourable outcomes.

Quality of life (T3) At T3, parents completed the 15item Pediatric Quality of Life Inventory (PedsQL), reporting their child's problems with physical, emotional, social and school functioning on a 5-point Likert scale ("never" to "almost always"). Scores were transformed to a 0-100 scale; higher scores indicated more favourable outcomes. The total score was used in analyses. The PedsQL has established feasibility, validity and reliability [35]. 
Self-esteem (T3) The Harter's Self-Perception Profile for Children (SPPC) [36] assessed global self-worth and scholastic, social, and athletic competence (T3). Children responded to 24 items by indicating with which of two statements they identified most (e.g. "some kids often forget what they learn" or "other kids can remember things easily") and then stating if the statement is "sort of true for me" or "really true for me". Items are scored on a 1-4 scale. Items within subscales were summed; higher scores indicate more favourable outcomes. The SPPC has established reliability and validity [36].

Strengths and difficulties (T3) Parents completed the Strengths and Difficulties Questionnaire (SDQ; T3), a brief behavioural screening tool with items on 25 positive and negative attributes $[37,38]$. Items are scored on a 3-point Likert scale ('not true' to 'certainly true'). Two summary scales, total difficulties and prosocial behaviour, were used as outcomes in analyses. Responses are reverse-scored where necessary and summed. The total difficulties score ranges from 0 to 40 (higher scores indicate more difficulties); prosocial scores range from 0 to 10 (higher scores represent more prosocial behaviour) [39]. Multiple studies support reliability and validity of the SDQ [40].

\section{Educational outcomes}

NAPLAN (age 8-9 years) Academic achievement was assessed by data linkage (with parent consent) with Year 3 (age approximately 8-9 years) results from the standardised National Assessment Program - Literacy and Numeracy (NAPLAN) [41]. NAPLAN has established reliability and validity [42]. These data were attained from the Victorian Curriculum and Assessment Authority. Achievement is assessed across five domains: language (grammar, punctuation), reading, writing, spelling and numeracy. An achievement score is calculated for each domain based on the number of correct items and then converted to a scale score $(0-1000$, higher scores indicate greater achievement).

\section{Confounders ( $\mathrm{T} 1$ )}

Child age at T1 (calculated from parent-reported child date of birth), sex, and maternal education (proxy for socioeconomic position) were included in each model as confounders. BMI-z scores (T1) were included as confounders in analyses with BMI-z scores as outcomes. No other outcome variables were assessed at T1. Sex and age standardized z-scores for height (T1) were included as confounders where BMD and BMC variables were outcomes.

\section{Statistical analyses}

Children were categorised at T1 as meeting/not meeting: 1) each individual guideline (for Aims 1 and 2); and 2) all guidelines (for Aim 3) at T1. Descriptive statistics for compliance, outcomes and confounders, were calculated. Multilevel, mixed effect, multivariable linear regression models were used to assess outcomes with normal, continuous distributions. Only 2 outcome variables, the SDQ prosocial score (ordered categorical) and history of fractures (dichotomous), did not meet assumptions for linear regression. Analyses for these outcome variables used ordered logistic regression and multilevel, mixed effects multivariable logistic regression, respectively. Analyses (in Stata SE 15.0) controlled for baseline confounders and clustering by center of recruitment [43]. Associations were examined for compliance with: 1) all guidelines (Aim 3; Model 1); 2) each guideline independently (Aim 1; Model 2); and 3) each guideline when adjusting for compliance with each of the other guidelines (Aim 2; Model 3) with each outcome variable in separate analyses. Complete case analyses were undertaken for each model.

\section{Results}

Children were 4.6 years old $(\mathrm{SD}=0.70)$ at baseline, $53 \%$ were boys and $62 \%$ were from high, $31 \%$ from mid and $7 \%$ from low socio-economic families as indicated by maternal education. Most children met PA (89\%) and sleep (93\%) guidelines; only $23 \%$ met the screen-time guideline. Overall, 20\% of children met all 3 guidelines. (See Supplementary Table 1 for T1 descriptive statistics.)

Regression analyses results for physiological outcomes are presented in Table 1. Meeting all 3 guidelines at T1 was inversely associated with BMI z-score at T3 $(\mathrm{b}=-$ $0.26,95 \% \mathrm{CI}-0.47,-0.05)$. At $\mathrm{T} 3.5$, meeting the PA guideline was positively associated with total body BMD and with total body BMC, independent of meeting each of the other guidelines.

No associations were evident between compliance and psychosocial outcomes (Table 2). Results of regression analyses for educational outcomes are presented in Table 3. Meeting sleep guidelines was associated with higher reading $(\mathrm{b}=37.60,95 \% \mathrm{CI} 6.74,68.46)$, spelling $(b=34.95$, 95\%CI $6.65,63.25)$, numeracy $(b=39.09$, $95 \% \mathrm{CI} 11.75,66.44)$ and language $(\mathrm{b}=44.31,95 \% \mathrm{CI}$ $11.77,76.85)$ scores at $8-9$ years of age when examined in individual models (Model 2). When associations were adjusted for compliance with other guidelines, results were similar and compliance with the sleep guideline was also associated with writing achievement $(b=25.93$, $95 \%$ CI 0.30, 51.57). No associations with educational outcomes were evident for meeting either PA or screentime guidelines. 


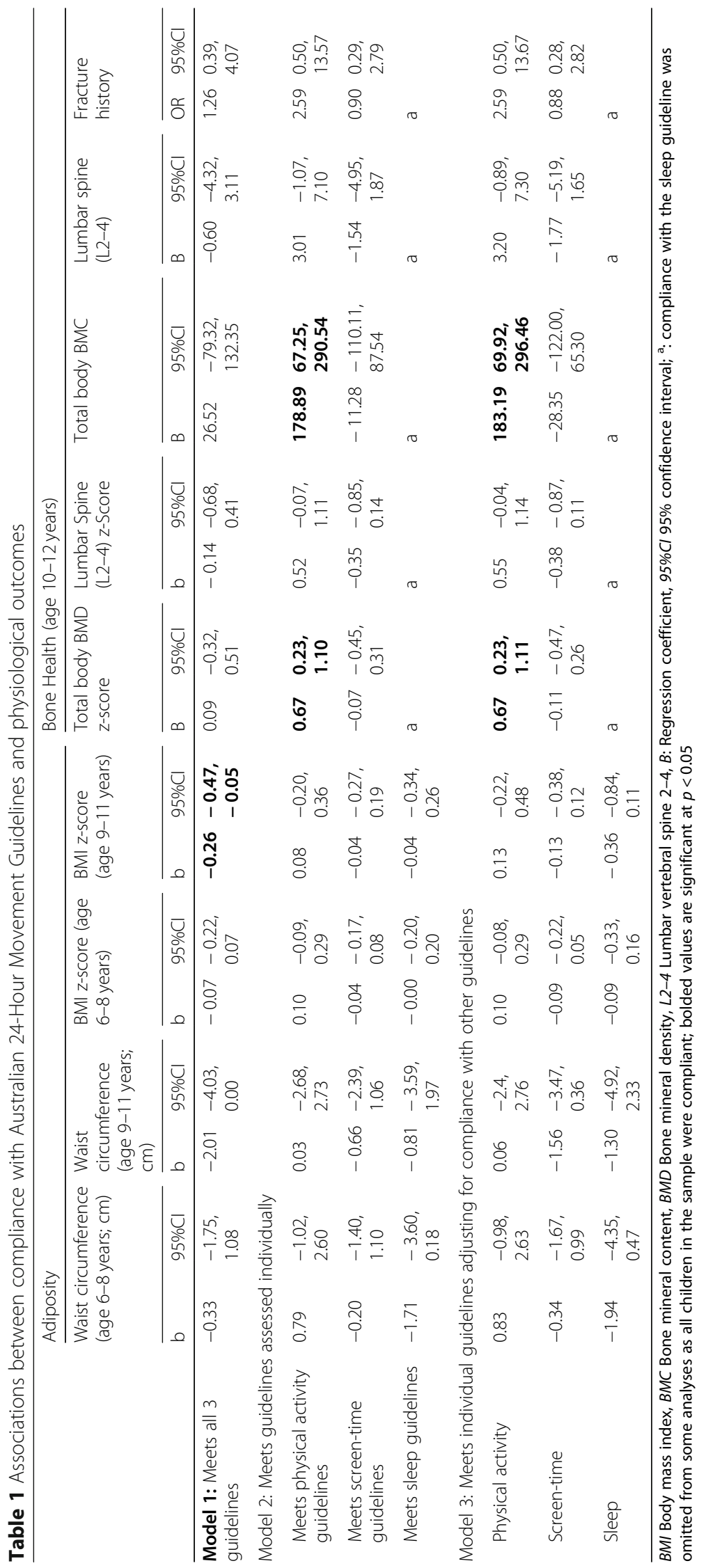




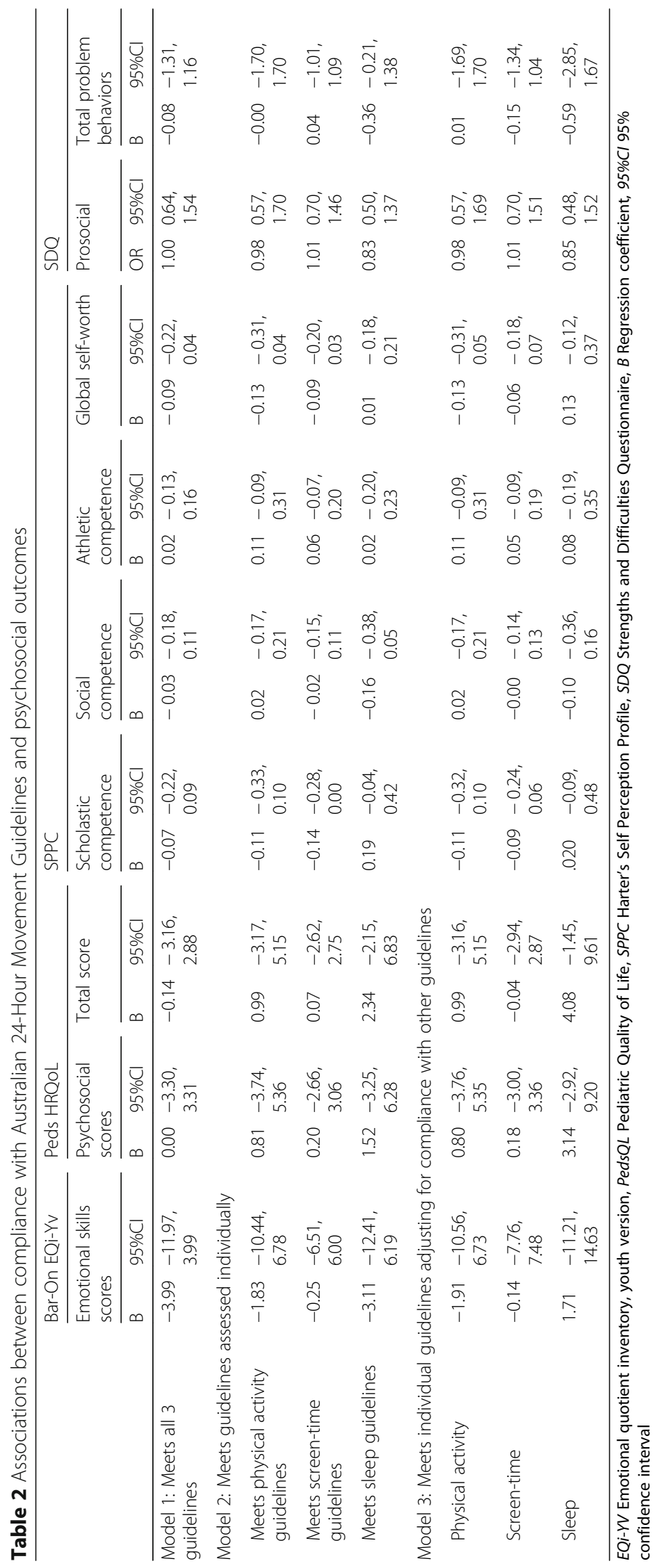


Table 3 Associations between compliance with Australian 24-Hour Movement Guidelines and educational outcomes

\begin{tabular}{|c|c|c|c|c|c|c|c|c|c|c|}
\hline & \multicolumn{2}{|l|}{ Reading } & \multicolumn{2}{|l|}{ Writing } & \multicolumn{2}{|l|}{ Spelling } & \multicolumn{2}{|c|}{ Numeracy } & \multicolumn{2}{|c|}{$\begin{array}{l}\text { Language (grammar } 8 \\
\text { punctuation) }\end{array}$} \\
\hline & $\mathrm{B}$ & $95 \% \mathrm{Cl}$ & B & $95 \% \mathrm{Cl}$ & B & $95 \% \mathrm{Cl}$ & B & $95 \% \mathrm{Cl}$ & B & $95 \% \mathrm{Cl}$ \\
\hline $\begin{array}{l}\text { Model 1: Meets all } 3 \\
\text { guidelines }\end{array}$ & 6.28 & $\begin{array}{l}-15.66 \\
28.21\end{array}$ & 9.26 & $\begin{array}{l}-5.67 \\
24.20\end{array}$ & 12.80 & $\begin{array}{l}-7.34 \\
32.94\end{array}$ & 6.31 & $\begin{array}{l}-13.07 \\
25.69\end{array}$ & 9.49 & $\begin{array}{l}-14.01 \\
32.99\end{array}$ \\
\hline \multicolumn{11}{|c|}{ Model 2: Meets individual guidelines assessed individually } \\
\hline $\begin{array}{l}\text { Meets physical activity } \\
\text { guidelines }\end{array}$ & -19.20 & $\begin{array}{l}-49.94 \\
8.54\end{array}$ & -9.20 & $\begin{array}{l}-28.10 \\
9.69\end{array}$ & -10.98 & $\begin{array}{l}-36.16 \\
14.20\end{array}$ & -13.91 & $\begin{array}{l}-38.20 \\
10.38\end{array}$ & -12.89 & $\begin{array}{l}-41.3 \\
15.84\end{array}$ \\
\hline Meets screen-time guidelines & -1.45 & $\begin{array}{l}-20.67 \\
17.80\end{array}$ & 0.24 & $\begin{array}{l}-12.81 \\
13.29\end{array}$ & -3.75 & $\begin{array}{l}-21.69 \\
14.19\end{array}$ & -1.41 & $\begin{array}{l}-18.51 \\
15.69\end{array}$ & -5.25 & $\begin{array}{l}-25.97 \\
15.47\end{array}$ \\
\hline Meets sleep guidelines & 37.60 & $\begin{array}{l}6.74 \\
68.46\end{array}$ & 20.70 & $\begin{array}{l}-0.08 \\
41.47\end{array}$ & 34.95 & $\begin{array}{l}6.65 \\
63.25\end{array}$ & 39.09 & $\begin{array}{l}11.75 \\
66.44\end{array}$ & 44.31 & $\begin{array}{l}11.77 \\
76.85\end{array}$ \\
\hline \multicolumn{11}{|c|}{ Model 3: Meets individual guidelines adjusting for compliance with other guidelines } \\
\hline $\begin{array}{l}\text { Meets physical activity } \\
\text { guidelines }\end{array}$ & -18.68 & $\begin{array}{l}-46.03 \\
8.67\end{array}$ & -9.04 & $\begin{array}{l}-27.83 \\
9.74\end{array}$ & -10.74 & $\begin{array}{l}-35.59 \\
14.12\end{array}$ & -13.81 & $\begin{array}{l}-37.76 \\
10.14\end{array}$ & -12.64 & $\begin{array}{l}-41.11 \\
15.82\end{array}$ \\
\hline Meets screen-time guidelines & 2.25 & $\begin{array}{l}-18.02 \\
22.52\end{array}$ & 5.37 & $\begin{array}{l}-8.56 \\
19.29\end{array}$ & -1.02 & $\begin{array}{l}-19.59 \\
17.54\end{array}$ & 1.20 & $\begin{array}{l}-16.63 \\
19.03\end{array}$ & 0.03 & $\begin{array}{l}-21.64 \\
21.71\end{array}$ \\
\hline Meets sleep guidelines & 53.23 & $\begin{array}{l}14.98 \\
91.48\end{array}$ & 25.93 & $\begin{array}{l}0.30 \\
51.57\end{array}$ & 56.10 & $\begin{array}{l}22.04 \\
90.17\end{array}$ & 55.74 & $\begin{array}{l}22.97 \\
88.50\end{array}$ & 61.07 & $\begin{array}{l}21.41 \\
100.73\end{array}$ \\
\hline
\end{tabular}

$B$ Regression coefficient, $95 \% \mathrm{Cl}$ 95\% confidence intervals; bolded values are significant at $p<0.05$

\section{Discussion}

This study examined Australian preschoolers' compliance with Canadian/Australian 24-Hour movement guidelines and prospective associations with physiological, psychosocial and educational outcomes. Although only $20 \%$ of children met all guidelines, most met sleep (93\%) and PA (89\%) guidelines. Compliance with the sleep guideline was associated with all educational outcomes when children were aged age 8-9 years in adjusted models. Compliance with the PA guideline was associated with total body BMD and BMC when children were aged 11-13 years. Meeting all guidelines was associated with more favourable (i.e., lower) BMI 6 years later (ages 9-11 years). Psychosocial outcomes were not associated with guideline compliance.

The proportion of children complying with the new 24-Hour Movement Guidelines for the Early Years is similar to a recent cross-sectional Australian study in preschoolers [18], but higher than studies in Australian toddlers [44] and Canadian preschoolers and toddlers $[19,45]$. Earlier studies are comparable only on screentime guidelines where estimates suggest compliance between 3 and 63\% [46, 47]. Variance between studies may be due to methodological or participant characteristics. For instance, compliance may be assessed by including all screen-time components (e.g. television, computer, electronic games) [23, 48], or combinations thereof (e.g. television, electronic games) [46, 49], or may be measured continuously [23] or in discrete categories [50]. This study captured data on TV/DVD/ video viewing, internet/computer use and electronic games. Future studies should consider including all forms of screen-time when estimating compliance and measuring time in behaviors continuously for more sensitive estimates.

A recent systematic review of preschoolers' PA and a variety of outcomes identified only 10 longitudinal studies and reported associations were inconsistent across studies [10]. Reported associations were evident across shorter time-frames (e.g. 12 months [51-53]) with only three studies showing associations with quality of life $[54,55]$ and fracture risk [56] over longer periods. Consistent with those studies, the current study found few associations of compliance with PA guidelines during early childhood and later outcomes, with the exception of bone health. Our findings concur with earlier review findings that PA during the pre-pubertal period, from as young as 6 years of age, is important for bone health [57], and extends previous work to highlight the importance of physical activity from early life. Some evidence suggests that the magnitude of the effects found in this study for associations between physical activity and bone health are meaningful [58-60]. Thus, all parents, early childhood educators and practitioners should encourage children to participate in adequate levels of PA as preschoolers.

In the current study, meeting screen-time guidelines during the preschool years was not associated with any of the assessed outcomes. A recent review examining associations between screen-time and health and developmental outcomes reported associations were primarily unfavorable or null [11]. Of the included studies, 19 were longitudinal and reported associations of preschoolers' screen-time with outcomes 1 to 9 years later. 
Associations of screen-time with psychosocial outcomes were primarily null, as in the current study, while those with cognitive outcomes were mixed [11]. Differences in findings may be attributable to differences in methodologies, including measurement of screen-time or types of devices used, or where a continuous measure of screen-time was used which would allow for identification of potential dose-response associations [61, 62]. Future studies exploring dose-response associations are required [11]. Research investigating associations between use of different devices and associations with outcomes is also warranted.

Meeting the sleep guideline was consistently and strongly associated with educational outcomes. The current study found differences in NAPLAN scores of up to 61 points between those meeting and not meeting the sleep guideline. This test score difference equates to change of approximately one performance band, or between meeting and not meeting national minimum standards $[63,64]$. Previous longitudinal research suggests that shorter sleep duration during early childhood may be associated with poorer outcomes for adiposity, emotion regulation and cognitive outcomes, and not associated with psychosocial outcomes [9]. However, findings between studies were mixed [9]; only 1 prospective study has examined preschoolers' sleep and later cognitive outcomes [65]. That study found children's night-time sleep duration at 3 years was associated with cognitive ability and children with higher cognitive ability at 3 years maintained higher abilities over a 3-year period [65]. Other research indicates that preschoolers' cognitive ability is predictive of academic achievement during primary school [66]. Thus it may be that preschoolers' sleep is associated with educational achievement, as evident in this study, through early cognitive ability. However, this remains to be tested in future research.

This study also explored associations of compliance with all guidelines. Few studies have previously explored such associations in preschoolers [8, 19, 21, 67], and only three studies have reported prospective associations of behaviours [20,22] or compliance with guidelines [21] and later outcomes. Those studies found that neither behaviors nor compliance with guidelines were associated with indicators of adiposity across one to four years. Similarly, the current study found no association between compliance with all guidelines at baseline and BMI z-score 3 years later but did find a significant inverse association between compliance and BMI z-score 6 years later. Previous research suggests that the magnitude of this association may be clinically meaningful [68]. It may be that early propensity for healthful behaviors, characterized here by meeting all guidelines, is supportive or indicative of healthful behaviors generally over time, which subsequently manifests in the identified association. Additionally, it may be necessary for children to have prolonged exposure over time to health behaviours for associations with outcomes such as BMI to become evident. Thus, the longer follow-up time in this study may be necessary for associations to be identifiable. It is noteworthy that compliance with the individual guidelines was not associated with BMI over time, despite compliance with all guidelines showing a favourable association with BMI 6 years later. Thus, it is possible that favourable outcomes for some variables, such as BMI, rely on children participating in a range of healthy behaviours.

Findings from this study highlight opportunities for future research. Given the number of null associations identified here, updated guidelines may not accurately identify the most appropriate thresholds for each behavior beneficial for all outcomes. Although current guidelines are based on the best available evidence, reviews undertaken to establish those guidelines highlighted that evidence to identify daily thresholds is insufficient and is of low to moderate quality [2]. Thus research should examine prospective associations between continuous values of each behavior and multiple outcomes to identify thresholds to better inform future guidelines. In particular, strong and consistent associations between compliance with the sleep guideline and children's educational outcomes warrant further attention. Additionally, behavior at a single time point may not be sufficient to predict future outcomes. Rather, behavior across time points may be a stronger predictor of outcomes. Thus, research should endeavor to establish associations of behaviors across time with later outcomes and future guidelines may reflect this. Characteristics of these behaviors which are not considered in current guidelines may also be important. For instance, future studies should investigate associations of characteristics of behaviours with later outcomes. These may include: type of PA (e.g. individual, structured [10]) or screen-time (e.g. TV, educational apps), caregiver interaction [6971], patterns [11, 72] (e.g. short, sustained), timing (e.g. screen-time immediately before bed [73]), sleep onset/ waking times, and sleep quality.

\section{Strengths and limitations}

This study helps to address gaps recognized in evidence informing the guidelines $[9,10]$. Strengths of the study include use of an objective measure of physical activity in a large sample of preschool children. The inclusion of multiple types of electronic media when assessing screen-time is noteworthy, since previous research has focused mainly on TV viewing [11]. Further strengths are the prospective design providing evidence of temporal associations, inclusion of exposure and outcome variables with established psychometric properties, an 
objective measure of PA and multiple outcomes. In addition to multiple strengths, this study also has some limitations that should be noted. NAPLAN tests provide a point-in-time estimates of children's literacy and numeracy and are intended for use in combination with other school-based assessment programs not available for inclusion in this study [74]. The small proportion (7\%) of children who did not meet the sleep guideline may be qualitatively different from those who did, and may help explain differences in outcomes. However, this is beyond the scope of this study. The response rate was $11 \%$ and a self-selected sample. This may mean that the results are not generalizable to the Australian population. However, a large, heterogenous sample of children across multiple sites was recruited. Additionally, the sample was comparable with the Australian population on important demographic characteristics. For instance, when characteristics of this sample are compared with the Australian population, $70 \%$ of parents in this sample were born in Australia as were $70 \%$ of parents in the total population, $67 \%$ vs $58 \%$ of parents have postsecondary qualifications, and $88 \%$ vs $78 \%$ of families are dual-parent, respectively [75]. Thus, these findings are likely to be generalizable to children in Australia. While we recruited from centres across socioeconomic strata, only a small proportion of the final sample represented this demographic. Data from 2 of the exposure variables, and most of the outcome variables, are subjective; results may vary if more objective data are available. Not all outcomes were assessed at all time points due to evolution in the focus of the study. While this limits the ability to directly compare between outcome measures, it adds breadth to the range of outcomes that can be commented on in this study.

\section{Conclusion}

This is the first study to examine longitudinal associations between meeting the integrated movement guidelines during preschool and health and developmental outcomes. It found consistent associations between compliance with PA guidelines during early childhood and future bone health, and between compliance with sleep guidelines during early childhood and later educational outcomes. This study highlights the benefits of meeting guidelines during early childhood which enables children to maximise their later health and educational potential.

\section{Acknowledgements}

NAPLAN data were provided by the Victorian Curriculum and Assessment Authority (VCAA). The VCAA was not associated with and does not endorse the analysis, comments or findings in this publication.

\section{Authors' contributions}

TH made substantial contributions to the conception and design of the work, to acquisition, analysis and interpretation of data, and drafted sections of the manuscript. AT made substantial contributions to the conception and design of the work and interpretation of data. AW made substantial contributions to the acquisition and interpretation of data and drafted some sections of the paper. RD made substantial contributions to the conception of the work, acquisition, analysis and interpretation of data, and drafted some sections. AO made substantial contributions to the conception of the work and interpretation of analysis. DC and AC made substantial

contributions to the design of the work and interpretation of data. $\mathrm{KH}$ made substantial contributions to the conception and design of the work, acquisition and interpretation of data. All authors approved the submitted version and agree to be personally accountable for their own contributions and that any questions related to the accuracy of integrity of the work have been resolved and documented.

\section{Funding}

TH was supported by a National Health and Medical Research Council Early Career Fellowship (APP1070571). KDH is supported by an Australian Research Council Future Fellowship (FT130100637) and an Honorary Heart Foundation Future Leader Fellowship (100370). AW is a recipient of a Postgraduate Scholarship from Deakin University. AT was supported by a National Heart Foundation of Australia Future Leader Fellowship (Award 100046). HAPPY was funded by Deakin University $(\mathrm{T} 1, \mathrm{~T} 3.5)$ and the Australia Research Council (DP110101434, DP140100554; T2, T3). The funders played no role in the design of this study during its execution, analyses, interpretation of the data, or decision to submit results.

\section{Availability of data and materials}

The dataset supporting the conclusions of this article is available on request from the authors pending ethical clearance.

\section{Ethics approval and consent to participate}

The Deakin University Human Research Ethics Committee (EC291-2007) and the Victorian Department of Education and Early Childhood Development provided ethical approval for the study. Parents in all participating families provided written, informed consent and children provided verbal assent at each measurement occasion.

\section{Consent for publication}

Not applicable.

\section{Competing interests}

The authors declare that they have no competing interests.

\section{Author details}

${ }^{1}$ Institute for Physical Activity and Nutrition (IPAN), School of Exercise and Nutrition Science, Deakin University, 1 Gheringhap Street, Geelong, VIC 3220, Australia. ${ }^{2}$ Alliance for Research in Exercise, Nutrition and Activity (ARENA), School of Health Sciences, University of South Australia, Adelaide, Australia. ${ }^{3}$ Australian Institute for Musculoskeletal Sciences (AMISS), St. Albans, Melbourne, VIC, Australia. ${ }^{4}$ Early Start, Faculty of Social Sciences, University of Wollongong, Wollongong, Australia. ${ }^{5}$ Illawarra Health and Medical Research Institute, Wollongong, Australia. ${ }^{6}$ Mary Mackillop Institute for Health Research, Australian Catholic University, Melbourne, Australia.

Received: 28 August 2019 Accepted: 17 February 2020

Published online: 10 March 2020

\section{References}

1. Ministry of Health. Sit less, move move, sleep well: active play guidelines for under fives. Wellington: Ministry of Health; 2017. http://www.health.govt.nz/ publication/sit-less-move-more-sleep-well-active-play-guidelines-under-fives. Accessed 26 Oct 2017

2. Tremblay MS, Chaput J-P, Adamo KB, et al. Canadian 24-Hour movement guidelines for the early years ( $0-4$ years): an integration of physical activity, sedentary behaviour, and sleep. BMC Public Health. 2017;17(5):874. https:// doi.org/10.1186/s12889-017-4859-6.

3. Department of Health. Australian 24-Hour Movement Guidelines for the Early Years. Canberra: Commonwealth of Australia, Department of Health; 2017. http://www.health.gov.au/internet/main/publishing.nsf/content/ health-pubhlth-strateg-phys-act-guidelines\#npa05. Accessed 22 Nov 2017. 
4. Chaput JP, Carson V, Gray CE, Tremblay MS. Importance of all movement behaviors in a 24-Hour period for overall health. Int J Environ Res Public Health. 2014;11(12):12575-81. https://doi.org/10.3390/ijerph111212575.

5. Saunders TJ, Gray CE, Poitras VJ, et al. Combinations of physical activity, sedentary behaviour and sleep: relationships with health indicators in school-aged children and youth. Appl Physiol Nutr Metab. 2016;41(6 Suppl 3):S283-93. https://doi.org/10.1139/apnm-2015-0626.

6. Tremblay MS, Carson V, Chaput JP, et al. Canadian 24-Hour movement guidelines for children and youth: an integration of physical activity, sedentary behaviour, and sleep. Appl Physiol Nutr Metab. 2016;41(6 Suppl 3):S311-27. https://doi.org/10.1139/apnm-2016-0151.

7. Carson V, Tremblay MS, Chaput JP, Chastin SF. Associations between sleep duration, sedentary time, physical activity, and health indicators among Canadian children and youth using compositional analyses. Appl Physiol Nutr Metab. 2016:41(6 Suppl 3):S294-302. https://doi.org/10.1139/apnm2016-0026.

8. Kuzik N, Poitras VJ, Tremblay MS, Lee EY, Hunter S, Carson V. Systematic review of the relationships between combinations of movement behaviours and health indicators in the early years (0-4 years). BMC Public Health. 2017; 17(Suppl 5):849. https://doi.org/10.1186/s12889-017-4851-1.

9. Chaput JP, Gray CE, Poitras VJ, et al. Systematic review of the relationships between sleep duration and health indicators in the early years (0-4 years). BMC Public Health. 2017;17(Suppl 5):855. https://doi.org/10.1186/s12889017-4850-2.

10. Carson $V$, Lee EY, Hewitt $L$, et al. Systematic review of the relationships between physical activity and health indicators in the early years (0-4 years). BMC Public Health. 2017;17(Suppl 5):854. https://doi.org/10.1186/s12889017-4860-0.

11. Poitras VJ, Gray CE, Janssen X, et al. Systematic review of the relationships between sedentary behaviour and health indicators in the early years (0-4 years). BMC Public Health. 2017;17(Suppl 5):868. https://doi.org/10.1186/ s12889-017-4849-8.

12. Certain LK, Kahn RS. Prevalence, correlates, and trajectory of television viewing among infants and toddlers. Pediatr. 2002;109:634-42. https://doi. org/10.1192/bjp.bp.108.049619.

13. Jones RA, Hinkley T, Okely AD, Salmon J. Tracking physical activity and sedentary behavior in childhood: a systematic review. Am J Prev Med. 2013; 44(6):651-8. https://doi.org/10.1016/j.amepre.2013.03.001.

14. World Health Organization. Guidelines on physical activity, sedentary behaviour and sleep for children under 5 years of age. World Health Organization. 2019. https://apps.who.int/iris/handle/10665/311664. License: CC BY-NC-SA 3.0 IGO.

15. Sallis JF, Owen N, Fotheringham MJ. Behavioral epidemiology: a systematic framework to classify phases of research on health promotion and disease prevention. Ann Behav Med. 2000;22(4):294-8.

16. Okely $A D$, Ghersi $D$, Hesketh $K D$, et al. A collaborative approach to adopting/adapting guidelines - the Australian 24-Hour Movement Guidelines for the Early Years (birth to 5 years): an integration of physical activity, sedentary behavior, and sleep. BMC Public Health. 2017;17(5):869. https://doi.org/10.1186/s12889-017-4867-6.

17. De Craemer M, McGregor D, Androutsos O, Manios Y, Cardon G. Compliance with 24-Hour movement behaviour guidelines among Belgian pre-school children: the ToyBox-study. Int J Environ Res Public Health. 2018; 15(10):2171.

18. Cliff DP, McNeill J, Vella SA, et al. Adherence to 24-Hour movement guidelines for the early years and associations with social-cognitive development among Australian preschool children. BMC Public Health. 2017;17(Suppl 5):857. https://doi.org/10.1186/s12889-017-4858-7.

19. Chaput JP, Colley RC, Aubert S, et al. Proportion of preschool-aged children meeting the Canadian 24-Hour movement guidelines and associations with adiposity: results from the Canadian health measures survey. BMC Public Health. 2017;17(Suppl 5):829. https://doi.org/10.1186/ s12889-017-4854-y.

20. Berglind D, Ljung R, Tynelius P, Brooke HL. Cross-sectional and prospective associations of meeting 24-Hour movement guidelines with overweight and obesity in preschool children. Pediatr Obes. 2018;13(7):442-9. https:// doi.org/10.1111/ijpo.12265.

21. Ip EH, Saldana S, Trejo G, et al. Physical activity states of preschool-aged Latino children in farmworker families: predictive factors and relationship with BMI percentile. J Phys Act Health. 2016;13(7):726-32. https://doi.org/10. 1123/jpah.2015-0534
22. Taylor R, Haszard J, Meredith-Jones K, et al. 24-Hour movement behaviors from infancy to preschool: cross-sectional and longitudinal relationships with body composition and bone health. Int J Behav Nutr Phys Act. 2018; 15(1):1-14.

23. Hinkley T, Salmon J, Okely AD, Crawford D, Hesketh K. Preschoolers' physical activity, screen time, and compliance with recommendations. Med Sci Sports Exerc. 2012;44(3):458-65. https://doi.org/10.1249/MSS. ob013e318233763b.

24. Sanderson S, Tatt ID, Higgins JPT. Tools for assessing quality and susceptibility to bias in observational studies in epidemiology: a systematic review and annotated bibliography. Int J Epidemiol. 2007;36(3):666-76.

25. Vandenbroucke JP, Von Elm E, Altman DG, et al. Strengthening the reporting of observational studies in epidemiology (STROBE): explanation and elaboration. PLoS Med. 2007;4(10):e297-1654. https://doi.org/10.1371/ journal.pmed.0040297.

26. Cliff DP, Reilly JJ, Okely AD. Methodological considerations in using accelerometers to assess habitual physical activity in children aged $0-5$ years. $J$ Sci Med Sport. 2009;12(5):557-67. https://doi.org/10.1016/j.jsams.2008.10.008.

27. Sirard JR, Trost SG, Pfeiffer KA, Dowda M, Pate RR. Calibration and evaluation of an objective measure of physical activity in preschool children. J Phys Act Health. 2005;2(3):345. https://doi.org/10.1123/jpah.2.3.345.

28. Hinkley T, O'Connell E, Okely AD, Crawford D, Hesketh K, Salmon J. Assessing volume of accelerometry data for reliability in preschool children. Med Sci Sports Exerc. 2012;44(12):2436-41. https://doi.org/10.1249/MSS. Ob013e3182661478.

29. Janssen X, Cliff DP, Reilly JJ, et al. Predictive validity and classification accuracy of actigraph energy expenditure equations and cut-points in young children. PLoS One. 2013;8(11). https://doi.org/10.1371/journal.pone.0079124.

30. Hinkley T, Salmon J, Okely AD, Crawford D, Hesketh K. The HAPPY study: development and reliability of a parent survey to assess correlates of preschool children's physical activity. J Sci Med Sport. 2012;15(5):407-17. https://doi.org/10.1016/j.jsams.2011.12.009.

31. Wake M, Salmon L, Waters E, Wright M, Hesketh K. Parent-reported health status of overweight and obese Australian primary school children: a crosssectional population survey. Int J Obes. 2002;26(5):716.

32. Australian Council for Health Physical Education and Recreation. Australian health and fitness survey 1985. Adelaide: ACHPER Publications1985; 1985.

33. Cole T, Bellizi M, Flegal K, Dietz W. Establishing a standard definition for child overweight and obesity worldwide: international survey. BMJ. 2000; 320:1240-8. https://doi.org/10.1136/bmj.320.7244.1240.

34. Bar-On R, Parker J. Bar-On emotional quotient inventory: youth version (EQ-i: YV): technical manual. Toronto: Multi-Health Systems; 2008.

35. Varni JW, Burwinkle TM, Seid M, Skarr D. The PEDSQL* 4.0 as a pediatric population health measure: feasibility, reliability, and validity. Ambul Pediatr. 2003;3(6):329-41.

36. Harter S. Self-perception profile for children: manual and questionnaires (grades 3-8). Denver: Department of Psychology, University of Denver; 2012.

37. Bourdon KH, Goodman R, Rae DS, Simpson G, Koretz DS. The strengths and difficulties questionnaire: U.S. normative data and psychometric properties. $J$ Am Acad Child Adolesc Psychiatry. 2005;44(6):557-64. https://doi.org/10. 1097/01.chi.0000159157.57075.c8.

38. Goodman R. Psychometric properties of the strengths and difficulties questionnaire. J Am Acad Child Adolesc Psychiatry. 2001;40(11):1337-45. https://doi.org/10.1097/00004583-200111000-00015.

39. Youth in Mind. Strengths and difficulties questionnaire: information for researchers and professionals about the strengths and difficulties questionnaire; 2013. http://www.sdqinfo.org. Accessed 17 June 2018.

40. Stone LL, Otten R, Engels R, Vermulst AA, Janssens J. Psychometric properties of the parent and teacher versions of the strengths and difficulties questionnaire for 4- to 12-year-olds: a review. Clin Child Fam Psychol Rev. 2010;13(3):254-74. https://doi.org/10.1007/s10567-010-0071-2.

41. Australian Curriculum Assessment and Reporting Authority. National Assessment Program-Literacy and numeracy; 2016. http://www.nap.edu.au/ naplan/naplan.html. Accessed 19 Oct 2017.

42. Australian Curriculum Assessment and Reporting Authority. National Assessment Program - literacy and Numberacy 2013: technical report. Sydney: ACARA; 2014.

43. Stata Corporation. Stata/SE 15.1 for windows. College Station: Stata Corporation; 2017

44. Santos R, Zhang Z, Pereira JR, Sousa-Sa E, Cliff DP, Okely AD. Compliance with the Australian 24-H Movement Guidelines for the Early Years: 
associations with weight status. BMC Public Health. 2017;17(Suppl 5):867. https://doi.org/10.1186/s12889-017-4857-8.

45. Lee EY, Hesketh KD, Hunter S, et al. Meeting new Canadian 24-hour movement guidelines for the early years and associations with adiposity among toddlers living in Edmonton, Canada. BMC Public Health. 2017; 17(Suppl 5):840. https://doi.org/10.1186/s12889-017-4855-x.

46. Berglind D, Tynelius P. Objectively measured physical activity patterns, sedentary time and parent-reported screen-time across the day in four-yearold Swedish children. BMC Public Health. 2017;18(1):69. https://doi.org/10. 1186/s12889-017-4600-5

47. Wijtzes Al, Jansen W, Jaddoe WW, et al. Ethnic background and television viewing time among 4-year-old preschool children: the generation $\mathrm{R}$ study. J Dev Behav Pediatr. 2013;34(2):63-71. https://doi.org/10.1097/DBP. 0b013e31827b163a.

48. Carson V, Spence JC, Cutumisu N, Cargill L. Association between neighborhood socioeconomic status and screen time among pre-school children: a cross-sectional study. BMC Public Health. 2010;10:367. https://doi. org/10.1186/1471-2458-10-367.

49. Carson V, Janssen I. Associations between factors within the home setting and screen time among children aged 0-5 years: a cross-sectional study. BMC Public Health. 2012:12:539. https://doi.org/10.1186/1471-2458-12-539.

50. Colley RC, Garriguet D, Adamo KB, et al. Physical activity and sedentary behavior during the early years in Canada: a cross-sectional study. Int J Behav Nutr Phys Act. 2013;10:54. https://doi.org/10.1186/1479-5868-10-54.

51. Klesges RC, Klesges $L M$, Eck LH, Shelton M-L. A longitudinal analysis of accelerated weight gain in preschool children. Pediatr. 1995;95:126-30

52. DuRant RH, Baranowski T, Rhodes T, et al. Association among serum lipid and lipoprotein concentrations and physical activity, physical fitness, and body composition in young children. J Pediatr. 1993;123(2):185-92.

53. Butte NF, Puyau MR, Wilson TA, et al. Role of physical activity and sleep duration in growth and body composition of preschool-aged children. Obesity (Silver Spring). 2016;24(6):1328-35. https://doi.org/10.1002/oby. 21489.

54. Wang $\mathrm{H}$, Sekine $\mathrm{M}$, Chen $\mathrm{X}$, Yamagami T, Kagamimori S. Lifestyle at 3 years of age and quality of life (QOL) in first-year junior high school students in Japan: results of the Toyama birth cohort study. Qual Life Res. 2008;17(2): 257-65. https://doi.org/10.1007/s11136-007-9301-6.

55. Vella SA, Cliff DP, Magee CA, Okely AD. Associations between sports participation and psychological difficulties during childhood: a two-year follow up. J Sci Med Sport. 2015;18(3):304-9. https://doi.org/10.1016/j.jsams. 2014.05.006

56. Wilson DK, Klesges $L M$, Klesges $R C$, et al. A prospective study of familial aggregation of blood pressure in young children. J Clin Epidemiol. 1992; 45(9):959-69.

57. Burrows M. Exercise and bone mineral accrual in children and adolescents. J Sports Sci Med. 2007;6(3):305-12

58. Ma J, Siminoski K, Alos $\mathrm{N}$, et al. The choice of normative pediatric reference database changes spine bone mineral density Z-scores but not the relationship between bone mineral density and prevalent vertebral fractures. J Clin Endocrinol Metab. 2015;100(3):1018-27. https://doi.org/10. 1210/jc.2014-3096.

59. Binkovitz LA, Henwood MJ. Pediatric DXA: technique and interpretation. Pediatr Radiol. 2007;37(1):21-31. https://doi.org/10.1007/s00247-006-0153-y.

60. Wildman SS, Henwood-Finley MJ. Pediatric DXA: a review of proper technique and correct interpretation. J Am Osteopathic Coll Radiol. 2012; 1(3):17-26.

61. Cheng S, Maeda T, Yoichi S, Yamagata Z, Tomiwa K. Early television exposure and children's behavioral and social outcomes at age 30 months. J Epidemiol. 2010;20(Suppl 2):S482-9.

62. Hinkley T, Verbestel V, Ahrens W, et al. Early childhood electronic media use as a predictor of poorerwell-being a prospective cohort study. JAMA Pediatr. 2014;168(5):485-92. https://doi.org/10.1001/jamapediatrics.2014.94.

63. Australian Curriculum Assessment and Reporting Authority. Score equivalence tables. Australian curriculum assessment and reporting authority; 2016. https://www.nap.edu.au/results-and-reports/how-tointerpret/score-equivalence-tables. Accessed 15 Dec 2019.

64. Victorian Curriculum and Assessment Authority. Understanding bands, scaled scores and national minimum standards. Victorian curriculum and assessment authority; 2015. http://usingassessmentdata.vcaa.vic.edu.au/ naplan/tut1_1/mod1.aspx. Accessed 15 Dec 2019.
65. Jung E, Molfese VJ, Beswick J, Jacobi-Vessels J, Molnar A. Growth of cognitive skills in preschoolers: impact of sleep habits and learning-related behaviors. Early Educ Dev. 2009;20(4):713-31. https://doi.org/10.1080/ 10409280802206890.

66. Chu FW, van Marle K, Geary DC. Predicting Children's Reading and mathematics achievement from early quantitative knowledge and domaingeneral cognitive abilities. Front Psychol. 2016;7:775. https://doi.org/10.3389/ fpsyg.2016.00775.

67. Carson V, Tremblay MS, Chastin SFM. Cross-sectional associations between sleep duration, sedentary time, physical activity, and adiposity indicators among Canadian preschool-aged children using compositional analyses BMC Public Health. 2017;17(Suppl 5):848. https://doi.org/10.1186/s12889017-4852-0.

68. Kolsgaard ML, Joner G, Brunborg C, Anderssen SA, Tonstad S, Andersen LF. Reduction in BMl Z-score and improvement in cardiometabolic risk factors in obese children and adolescents. The Oslo adiposity intervention study - a hospital/public health nurse combined treatment. BMC Pediatr. 2011;11:47. https://doi.org/10.1186/1471-2431-11-47.

69. Nathanson Al, Aladé F, Sharp ML, Rasmussen EE, Christy K. The relation between television exposure and executive function among preschoolers. Dev Psychol. 2014;50(5):1497-506. https://doi.org/10.1037/a0035714.

70. Nathanson Al, Fries PT. Television exposure, sleep time, and neuropsychological function among preschoolers. Media Psychol. 2014; 17(3):237-61. https://doi.org/10.1080/15213269.2014.915197.

71. Kostyrka-Allchorne K, Cooper NR, Simpson A. The relationship between television exposure and children's cognition and behaviour: a systematic review. Dev Rev. 2017;44:19-58. https://doi.org/10.1016/j.dr.2016.12.002.

72. Schlieber M, Han J. The sleeping patterns of head start children and the influence on developmental outcomes. Child Care Health Dev. 2018;44(3): 462-9. https://doi.org/10.1111/cch.12522.

73. Hale L, Guan S. Screen time and sleep among school-aged children and adolescents: a systematic literature review. Sleep Med Rev. 2015;21:50-8. https://doi.org/10.1016/j.smrv.2014.07.007.

74. Victorian Curriculum and Assessment Authority. National Assessment Program - literacy and numeracy testing (NAPLAN); 2016. http://www.vcaa. vic.edu.au/Pages/prep10/naplan/index.aspx. Accessed 26 Oct 2017.

75. Census of Population and Housing: Socio-Economic Indexes for Areas (SEIFA) 2033.0.55.001 [database on the Internet]. Australian bureau of statistics; 2011. Available from: http://www.abs.gov.au/AUSSTATS/abs@.nsf/ allprimarymainfeatures/6CD4E5CE952FEDBFCA257B3B001AC3E5 ?opendocument. Accessed: 8 Feb 2016.

\section{Publisher's Note}

Springer Nature remains neutral with regard to jurisdictional claims in published maps and institutional affiliations.

Ready to submit your research? Choose BMC and benefit from:

- fast, convenient online submission

- thorough peer review by experienced researchers in your field

- rapid publication on acceptance

- support for research data, including large and complex data types

- gold Open Access which fosters wider collaboration and increased citations

- maximum visibility for your research: over $100 \mathrm{M}$ website views per year

At BMC, research is always in progress.

Learn more biomedcentral.com/submissions 